\title{
ROLE OF INTERCULTURAL TRAINING IN A PROCESS OF HUMAN RESOURCE INTERNATIONALIZATION
}

\author{
[Role interkulturního tréninku v procesu internacionalizace lidských zdrojů] \\ Renata Čuhlová ${ }^{1}$, Muhammad Ismail Yar ${ }^{2}$ \\ ${ }^{1}$ Technical University of Liberec, Faculty of Economics, Studentska 1402/2, 46117 Liberec \\ Email:renata.cuhlova@tul.cz \\ ${ }^{2}$ University of Science and Technology Beijing, Dongling School of Economics and Management, Beijing \\ 100083 P.R.China \\ Email:mohd.ismail.yar@gmail.com
}

\begin{abstract}
The paper demonstrates the importance of intercultural training as a part of expatriation process with the aim to easily adapt in international assignment. Based on review of available training approaches, the research to obtain empirical data was conducted. The experience of a sample of 164 Czech expatriates from the multinational company in the Czech Republic was investigated via questionnaires regardless their host location. Findings illustrate the current practices and highlight weaknesses of their preparation process, such as insufficient timing of preparation, including accompanying families and overall accessibility to the training tools.
\end{abstract}

Keywords: expatriation, human resources, intercultural training, internationalization.

JEL classification: J61, M53

Doručeno redakci: 26.6.2018; Recenzováno: 28.6.2018; 2.7.2018; Schváleno k publikování: 19.9.2018

\section{Introduction}

Internationalization of business environment influences many of its aspects including human resources. Employees travel abroad to attend international trade fairs, meet their foreign counter partners, acquire new customers. Moreover, employees are also assigned to transfer know-how into foreign subsidiaries. In all these cases, their professional knowledge of the business is not enough to ensure great performance as expected since no matter how advanced technologies are used or how long the assignment takes, interaction with other people is always involved.

The lack of intercultural knowledge can be very costly for multinational companies. This might occur in terms of direct costs but also indirect costs of lower productivity or damaged business relationships (Hill 2010; Dowling et al. 2008; Lenartowicz et al. 2013). As Lenartowicz et al. (2013) and Kogut (2000) continue, these intercultural competences might become a competitive asset. The findings demonstrate that intercultural issues play indirect but important role in the processes of international expansion of companies via facilitating the interpersonal relationships of expatriate managers with the foreign culture counter partners (Rey et al. 2017).

As results of the study Global Mobility Trends Survey Report show, only $34 \%$ companies offer intercultural trainings to all their assigned employees (Brookfield GRS 2015). Intercultural training programs are however obligatory only in a quarter of firms. Due to this situation, many expatriates do not take part in any training before the departure. Similar findings are confirmed by the GLOBE study where $80 \%$ out of 127 responding managers working on assignment abroad said that their companies do not use any test for expatriate selection (Dorfman et al. 2012). In this gap, we can observe high potential for increasing the effectiveness of the expatriation process. Moreover, insufficient attention to the expatriate training is one of the most common critics towards human resource management of the multinational companies. 
Finally yet importantly, it is very crucial to consider the readiness of family members of the expatriate. According to the survey (ECA International 2017), cultural aspects are one of the main reasons of failure to adapt to the foreign assignment life. However only $18 \%$ employers offer cultural training to the whole family.

The article overviews the training methods of intercultural skills that have developed over time as the most commonly used training tools. Next, it presents and analyses primary data from the research focused on experience of Czech expatriates with pre-departure training and the findings display its effect on the adaptation process while on assignment abroad.

\section{Intercultural training methods}

As Puck et al (2008) specify, intercultural trainings in a business context are usually aimed for people who are in a contact with other cultures nationals, as for example members of multicultural teams, or who expatriates going to work to another countries. Moreover, the intercultural training is considered as the most effective way how to spread cultural knowledge and develop sensitivity in multinational companies (Black et al. 1992; Lenartowicz et al. 2014).

The type of training should differ based on work, environment, individuals and cultural factors (Brewster 1995). Bennett et al (2000) state that when conducting the intercultural training, the very first step is to set its purpose, goals and the needs of a training participant. Human resource management must incorporate three important variables in their approach of the selecting the appropriate training. These are: awareness with the future job position abroad, degree of interaction with the host nation and awareness of the host culture depending on the cultural distance between home and host culture (Mendenhall et al. 1995).

The first aim to create a framework that firms could use to manage the expatriate training was developed by Tung (1981). Categories of training defined according to their focus and content are identified as follows:

- Information about the environment and culture. The information about history, geography, climate, demographic situation, political and economic situation represent the facts-oriented intercultural training. Harrison (1994) says that from the past when there was an assumption that this kind of knowledge leads to an increase in empathy intercultural relations, today the facts-oriented intercultural training has only an informative function and creates a certain introduction of the whole intercultural preparation.

- Cultural assimilator. The short description of intercultural interactions with certain misunderstanding or conflict after which the several explanations of given situation follow As Morrise and Robie (2001) state, the reason of the wrong answer selection might be even more important than the actual answer because it helps to indicate mental patters of individuals. Besides the informative function, the cultural assimilator determines the diagnostics of participants' intercultural competences.

- Language training. Tung (1981) claims that language training helps not only to handle the conversation but foreign language study demonstrates the real motivation of the employee leaving abroad. The training should also include nonverbal communication and rules of request expressions. According to Harrison (1994), Lenartowicz et al (2014) and Tung and Andersen (1997), language preparedness should not be ignored even in case of accompanying family members because language skills present an important factor of adaptation in new environment and society. Besides that, the willingness to use a foreign language has greater impact on adaption that its real level (Mendenhall and Oddou 1988, Puck et al. 2008). 
- Training of cultural sensitivity/awareness displays expatriate's own values, tendencies and patterns of behaviour, as well as strong sides and weaknesses. As Mendenhall et al (1995) continues, it works on the assumption of understanding the own culture. Next, identification of the differences and application of new knowledge is possible (Morris and Robie 2001, Nový et al. 1996).

- Fields or pre-assignment trips for getting to know the future environment, meeting new colleagues. Moreover, the expatriate can use this time to manage the accommodation or other facilities for the accompanying family.

Black et al (1992) identified other training methods that can complement the above mentioned: movies that are suitable for the analysis of different situation, motivation and demonstration; books; role plays where expats play themselves or other typical representatives of the contrast cultures. Nový et al. (1996) claims that if the participants are in the roles of foreign culture, their personal experience is much stronger and valuable. Similar method is called simulation when managers are "put" into host culture to deal with people they do not understand.

Last but not least, case studies are another method in a form of detailed description of a problem and its analyses, diagnostics of cultural problems and finding an adequate solution afterwards. The participants should be able to deduce principles that they can use in intercultural conflicts in real situations (Harrison 1994).

Based on the content, we can distinguish between two main categories: culturally specific and culturally generalized trainings (Puck et al. 2008; Lenartowicz et al. 2014). The culturally specific intercultural training aims at preparing employees for a specific culture. On the other hand, culturally generalized intercultural training focuses on development of individual's competences and sensitization for cultural differences in general. The future expatriate can be prepared by the culturally generalized training for basic variations that can be experienced anywhere.

Some authors (Eschbach et al. 2001) support the idea to continue the training also after the arrival into the host country. According to their argumentation, this phase is a crucial period during assignment process and expatriate should be supported as in the beginning of assignment. Tung (1998) generally claims that intercultural training should be long term and the past of lifelong learning of the individual. In the selection of appropriate training methods, the cultural distance between home and host country of the expatriate should be taken into account as Mendenhall et al (1995) states. As it has already been mentioned, a bigger difference between the cultures means more difficult understanding of foreigners and adaptation to their culture.

The above-mentioned overview of methods of intercultural training shows currently used instruments aimed at developing intercultural competitions and smoothing the adaptation process in foreign culture.

\section{Methodology}

The research topic focused on intercultural trainings and intercultural preparedness of the internationally assigned employees. The aim was to investigate the experience of expatriates with intercultural training as an important part of the preparation for the host culture and a method to ease the adaptation process. 
The presented research was carried out in the headquarter of a multinational company in the Czech Republic. The company holds a unique position on the Czech market and the expatriation strategy represents one of the main pillars of Human resource management there as the existence of separate department of the International Assignments demonstrates. In average of last years, 170 expatriates are on assignment and majority (almost 80\%) are assigned for long term. In the time of the data collection, expatriates were located to 9 countries worldwide and 28 different locations. Overall, the company was chosen for its size, strategy, experiences and diversity that characterize the local expatriation process. In terms of the Czech environment, there is not another company with so many assignments that would be available for deduction of general conclusion on this topic.

Data for the present study was extracted from a mail questionnaire targeted at Czech expatriates assigned to work abroad. The targeted sample was chosen based on criteria stated in the literature review (Thomas and Lazarova 2006) as well as consultations with the company. The sample of Czech expatriates consisted of two categories:

- $\quad$ Current expatriates with experience of minimal three months already on assignment.

- $\quad$ Repatriates with maximal 6 months after return from assignment.

The sample was contacted regardless the host country of the assignment. Distribution and data collection were carried out in three phases from March 2016 to January 2017. A total of 302 Czech expatriates received the mail questionnaire through the internal distribution system in the organization. Out of 302 Czech expatriates, 164 expatriates and repatriates completed the questionnaire. The response rate was $54.3 \%$.

The Statistica 13 and Statgraphics programs were used for statistical analysis of dependency of intercultural adaptation in the host country on involvement in intercultural pre-departure preparation/training. The Kruskal-Wallis test was chosen based on characteristics of data. Thus, we derive the following hypotheses:

Hypothesis 1: Expatriate will be better adapted in the host country if participating in predeparture intercultural training.

Interpretation is based on comparison with significance level $\alpha=0.05$.

\subsection{Respondents}

The specific age was not investigated and therefore the exact average age cannot be calculated. The largest group of respondents (48\%) was in the range of 36-46 years old, next (40\%) in the range of 25-35 years. This result corresponds with previous studies that indicate the average age of expatriates as upper 30' and lower 40' (Bright 2008; Shmueli et al. 2005).

The gender split was $85 \%$ male and $14 \%$ female, which is similar to other studies with foreign assignees (Bhaskar-Shrinivas et al. 2005; Hechanova et al. 2003). Findings of Brookfield's study (2015) show that a relatively constant share of assigned women worldwide is about $20 \%$. The dominance of men can be explained by certain prejudices of foreigners towards women, secondly by lower willingness of companies to relocate women, and last but not least, lack of interest from women's prospect or their family reasons (Harris 2004).

For better identification of respondents, the company department within organization was under examination. The majority of them worked in Technical development (32\%), Logistics (25\%), 
Finance, Informational technologies and Law (19\%). The rest of respondents were from Sale \& Marketing, Purchasing and Human Resources.

The host country that expatriates were assigned to was Germany (41\%), a traditional business partner of the Czech Republic, followed by China (23\%), Russia (18\%), and India (5\%). Other countries were the United Kingdom, Slovakia, Spain, and Poland.

Respondents also ranked the size of their social contacts with foreigners including for example friends, colleagues, and family members. This question aimed to examine the level of international and intercultural environment in which an employee lives. Relationships with foreigners hold rather a minor position ( $0-25 \%$ share in total relationships) for almost 3/4 of respondents.

\section{Findings}

This chapter presents the questionnaire' findings. Firstly, the participation of employees on a preparatory training was investigated and usage of any other learning ways as well. The second topic concerned to the timing of the first information about the assignment and about the beginning of the intercultural preparation process. Third, the suggestions for improvement from the employees' point of view were examined. Last but not the least, the relation between intercultural training and consequent adaptation level while on international assignment was verified.

The total amount of $73 \%$ respondents attended intercultural pre-departure preparation. Out of them, $26 \%$ persons attended also professional training. $33 \%$ of future expatriates attended only professional preparation.

Training tools that a person got through from their initiative or provided by the company was a subject of another question. Respondents could choose from the following list: Intercultural training with personal attendance; language training; training on job specifics, informative materials about the culture of given country; aimed movie, music and books search; e-learning intercultural course; meeting with colleagues that already experienced work assignment in the country; others. The frequency of (not) usage of mentioned tools is displayed.

Figure 1: Training tools for foreign assignment

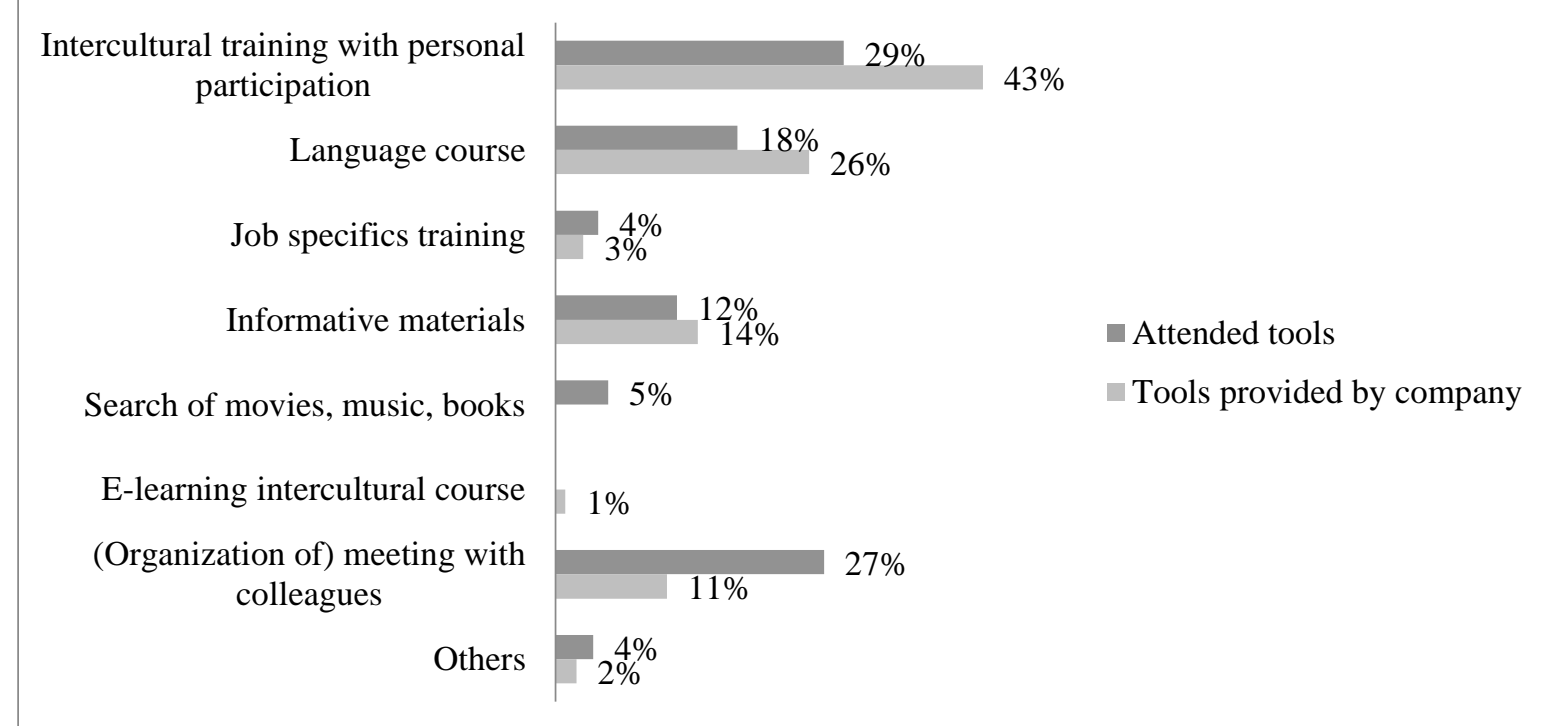

Source: Own analysis based on questionnaires' analysis 
As evident from the chart, although the company offers both intercultural and language trainings to the assigned employees, not everyone uses this opportunity. On the other hand, data shows that only $43 \%$ employees before departure were offered a possibility of intercultural training. Worthy to mention are also the findings regarding to the meeting with colleagues that had already experienced the stay in the given foreign locality. In more than double cases this meeting has been arranged from the own initiative of an employee and not via the human resource department.

When planning the trainings and preparations that should make the job, life and the whole adaption abroad easier, timing itself is very important. Moreover, it applies to the timing of the first information about assignments so the individual can start with any kind of preparation. The same applies to accompanying family members. In terms of time framework, following questions were asked: "How long before departure did you get the first information about your foreign assignment?" and "At what time before departure abroad did your intercultural preparation from the company's side start?" Chart 2 displays the responses' frequency.

Figure 2: Pre-departure preparation timing

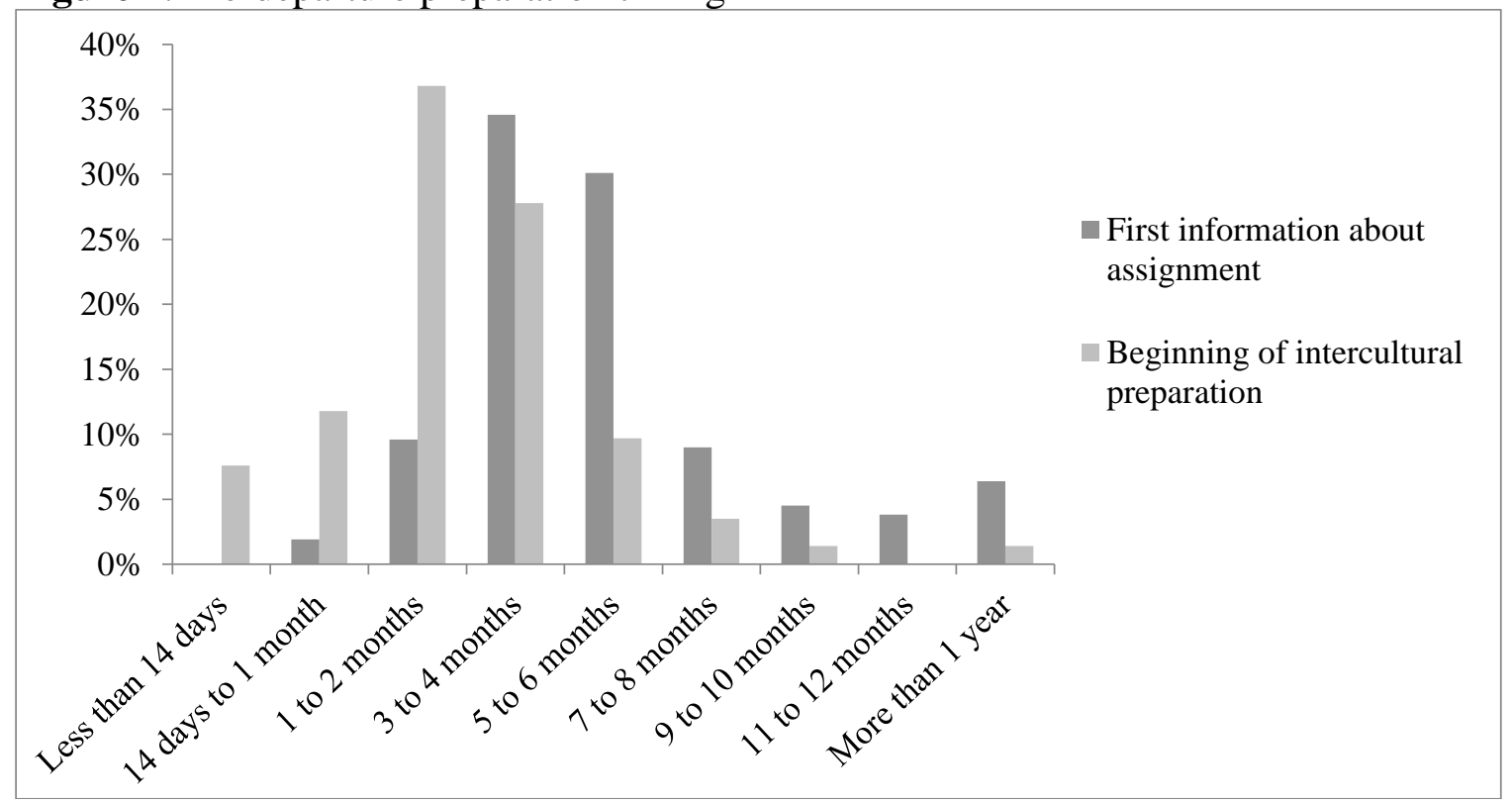

Source: Own analysis based on questionnaires' analysis

Data shows that most often (in $35 \%$ of cases), the first information about the assignment is given 3 to 4 months prior, and then in $30 \%$ of cases 5 to 6 months before departure. As it has been confirmed by the human resource department, this timing seems to be the most optimal one. Intercultural preparation started 1 to 2 months before the departure in $37 \%$ of cases which might be relatively late because the assignee usually deals with many organizational duties just before the departure and the intercultural training might not be the priority in that time. The best time to commence the intercultural preparation seems to be 3 to 4 months before the departure when the preparation process is not so intense but at the same time, it is a relevant matter for the future expatriate (as well as his/her accompanying family).

Recommendations and suggestions for improvement of intercultural preparation from the view of employees was next topic of the survey. The respondents could choose from eight options that are listed in table 1 according to the frequency of valid replies. Respondents could select more options. Almost $17 \%$ of respondents did not reply to this question thus we could assume that they were satisfied with the current offer of services and no improvement is needed. 
However, the reason might also be the incomplete list of possible replies or unwillingness to answer.

Table 1: Suggestions for intercultural preparation improvement

\begin{tabular}{|l|l|c|c|}
\hline \multirow{4}{*}{ Valid } & Category & Frequency & Percentage \\
\cline { 2 - 3 } & Meeting with someone that already experienced the assignment & 77 & $47 \%$ \\
\cline { 2 - 3 } & More intense language preparation & 59 & $36 \%$ \\
\cline { 2 - 3 } & More practical information about the foreign country & 57 & $35 \%$ \\
\cline { 2 - 3 } & Business trip to see the work environment and job specifics & 52 & $32 \%$ \\
\cline { 2 - 4 } & Specific case studies & 48 & $29 \%$ \\
\cline { 2 - 4 } & Training for work in multicultural teams & 32 & $20 \%$ \\
\cline { 2 - 4 } & More information about the cultural differences & 29 & $18 \%$ \\
\cline { 2 - 4 } & Longer intercultural training & 21 & $13 \%$ \\
\hline Missing & & 27 & $17 \%$ \\
\hline
\end{tabular}

Source: Own analysis based on questionnaires' analysis

Most of respondents (77) would welcome a meeting with someone that already experienced similar assignment. Next, expatriates-to-be would like to have more intense language courses (59 respondents) and more practical information about the foreign country ( 57 respondents). On the contrary, the current length of provided intercultural training seems optimal and only 21 respondents suggest a longer period.

Relation of dependency between intercultural training participation and the level of adaptation abroad was investigated as last. The adaption level was assessed by respondents on the scale 1 to 7 , when $1=$ completely non-adapted and $7=$ completely adapted, in totally 11 variables. These variables, stating for separate fields of adaption, are displayed in table 2 and can be classified into three main groups:

- Living environment - living conditions generally, accommodation conditions, food, shopping;

- Host country mentality - developing personal relations and spending free time with locals; accepting of non-written rules of behaviour and cultural standards; everyday communication with locals;

- Work environment - work environment generally; interaction with local colleagues; specific work requirements; performance standards and work expectations.

Table 2: Characteristics of distribution and variability for particular variables of adaptation

\begin{tabular}{|l|c|c|c|c|c|}
\hline \multirow{2}{*}{ Category } & \multicolumn{2}{|c|}{ Characteristics of distribution } & \multicolumn{2}{c|}{ Characteristics of variability } \\
\cline { 2 - 6 } & Mode & Median & $\begin{array}{c}\text { Arithmetic } \\
\text { mean }\end{array}$ & Variance & $\begin{array}{c}\text { Standard } \\
\text { deviation }\end{array}$ \\
\hline Accommodation conditions & 7 & 6 & 6,08 & 1,16 & 1,08 \\
\hline Food & 7 & 6 & 5,92 & 1,32 & 1,15 \\
\hline Shopping & 6 & 6 & 5,87 & 1,27 & 1,13 \\
\hline Living conditions generally & 6 & 6 & 5,65 & 1,09 & 1,05 \\
\hline \hline $\begin{array}{l}\text { Accepting of non-written rules of } \\
\text { behaviour and cultural standards }\end{array}$ & 6 & 6 & 5,54 & 1,34 & 1,16 \\
\hline Everyday communication with locals & 5 & 5 & 5,21 & 2,13 & 1,46 \\
\hline $\begin{array}{l}\text { Developing personal relations and } \\
\text { spending free time with locals }\end{array}$ & 4 & 4 & 4,81 & 2,48 & 1,57 \\
\hline $\begin{array}{l}\text { Performance standards and work } \\
\text { expectations }\end{array}$ & 6 & 6 & 5,78 & 1,27 & 1,13 \\
\hline Interaction with local colleagues & 6 & 6 & 5,76 & 1,06 & 1,03 \\
\hline Specific work requirements & 6 & 6 & 5,62 & 0,99 & 0,99 \\
\hline Work environment generally & 6 & 6 & 5,51 & 1,22 & 1,10 \\
\hline
\end{tabular}

Note: Scale 1-7, where $1=$ completely non-adapted to $7=$ completely adapted

Source: Own analysis based on questionnaires' analysis 
Adaption in terms of host country mentality and developing of relations with local inhabitants seems to be the most difficult issue. Altought the expatriate gets used to new environment consisting of the accomodation and different food offer, and despite his/her existance without bigger difficulties in the job, he/she does not really integrate into the host society.

Based on resulting values in following table 3 we can claim that the stated hypothesis and thus linear corelation with intercultural training participation was proved with three variables: the adaption on living conditions generally; accepting of non-written rules of behaviour and cultural standards; and everyday communication with locals. Contribution of intercultural training was proved in mentioned categories.

Table 3: Dependency relation between intercultural training participation and adaptation level

\begin{tabular}{|c|c|c|}
\hline Category & Kruskal-Wallis test & p-value \\
\hline Living conditions generally & 5,61 & 0,02 \\
\hline Accommodation conditions & 1,89 & 0,17 \\
\hline Food & 0,28 & 0,57 \\
\hline Shopping & 2,42 & 0,12 \\
\hline Developing personal relations and spending free time with locals & 1,62 & 0,20 \\
\hline Work environment generally & 1,52 & 0,22 \\
\hline Interaction with local colleagues & 0,10 & 0,76 \\
\hline Accepting of non-written rules of behaviour and cultural standards & 2,31 & 0,03 \\
\hline Specific work requirements & 1,95 & 0,16 \\
\hline Performance standards and work expectations & 0,00 & 0,99 \\
\hline Everyday communication with locals & 4,38 & 0,04 \\
\hline
\end{tabular}

Source: Own proceeding based on questionnaires' analysis

A positive finding is the above-average evaluation of the adaptation level as assessed by expatriates themselves. Developing of relationships with local inhabitants showed up to be an issue. Surprisingly, this finding stays the same regardless the destination country and does not matter if there is a dealing with German culture that is closer to Czechs or outside Europe. Activities of the human resource department in a host organization should therefore focus on a more intense contact of expatriates outside workplace.

All $(100 \%)$ respondents were willing to share their experiences and knowledge with other assigned colleagues. It confirms the previous findings (e.g. Nový and Schroll-Machl, 2007) that people with foreign experience like to share their experiences and actually welcome possibility to transmit them further.

\subsection{Discussion}

Our investigation provides an insight into the practice of intercultural preparation of Czech expatriates and its impact on adjustment in a host culture. Data shows the variety of tools offered by the company/employer as well as those experienced by expatriates from the own initiative. The comparison displays the motivation trend of the expatriates to use multiple sources of information about the host culture. This supports the idea of Tung and Andersen (1997) that the offered types of training programs should be rather complementary than mutually exclusive.

As researchers (Dowling et al. 2008) point out, duration of the training and also its intensity are factors influencing the outcomes and the extend of fulfilled expectations. According to the study of Lenartowicz et al. (2014), there is no clear conclusion based on previous research that would prove specific implications in this matter. Although we cannot confirm that both intensity and 
duration increases the training outcomes, we claim that due to reasons stated in the previous section of this paper, 3 to 4 months is viewed as the best time to start with the intercultural preparation. Besides that, it is hard to effectively absorb such a knowledge within short training period, especially when the trainee has to deal with many issues related to moving to another country, starting to work in new team, possibly relocating the whole family and others. As Tung (1998) argue, intercultural training should be a life-long process and preferably not focusing only on a specific country but more likely to get general awareness about the cultural differences.

As Lenartowicz et al. (2014), Thomas and Lazarova (2006) emphasize, repatriates are a great source of intercultural knowledge and appropriate experience but still remain without proper use. Majority of the respondents of the presented research recommends to incorporate a meeting with someone that already experienced similar assignment into the assignment preparation process. This is also supported by the data on chart 1 in the Findings section which firstly demonstrates the initiative of expatriates themselves to get into a contact with repatriates and secondly that there is still space for improvement from the company's side.

As a number of authors (for instance, Bhaskar-Shrinivas et al. 2005; Harris 2004; Puck et al. 2008) proposes, the intercultural training might significantly enhance the expatriate adaptation process in a host culture. On the other hand, according to the meta-analysis by Morris and Robie (2001), the impact of the training on expatriate adaptation can be overestimated. Our results show that the adaption of the research sample was above average. Host country mentality and development of relations with locals were identified as the most difficult issues. Pre-departure intercultural preparation proved to be a beneficial for the adaption on host living conditions generally, for easier acceptance of non-written rules of behaviour and cultural standards, and assignees saw its value for everyday communication with locals. In another forms of adaption and adjustment situation the effect was not confirm.

\section{Conclusion}

In today's rapidly growing globalized world where there is fierce competition in every branch of industry and on the other hand resources are limited, effective planning and scheduling play a crucial role in attaining the targets/deliverables as well as determine the success of the project. Human capital still remains the key asset and source of competitiveness not less than in the past decades. Internationalization of businesses includes the internationalization of human resources, and creates intercultural workplaces.

When comes to the expatriation process that is often a way of know-how transmission, its high financial demandingness reflects the importance of the research and highlights the crucial role of employees' intercultural skills management as well as their adaptation abroad.

The aim of this paper was to investigate the experience of expatriates with intercultural training and its role for the adaptation process in a host culture. The results were obtained via questionnaire among 164 Czech expatriates. The analysis included a testing of hypothesis whether the expatriate is better adapted in certain situations (totally 11 variables of adaptation was analysed) in the host country if participating in pre-departure intercultural training. This hypothesis was proved in three variables of adaption. Specifically, when expatriate participated in pre-departure intercultural training, he/she felt better adjusted to living conditions of the host country generally; accepting of non-written rules of behaviour and cultural standards; and everyday communication with locals. In other cases under investigation (accommodation conditions; food; shopping; developing personal relations and spending free time with locals; 
work environment generally; interaction with local colleagues; specific work requirements; performance standards and work expectations), the dependency was not proved and therefore the benefit of participation in pre-departure training was not confirmed.

Findings regarding the intercultural preparation of employees assigned to work abroad highlight the important issues that should hold the priority in the focus of human resource managers. Firstly, the personal meeting with an employee that has already experienced a similar assignment should be covered in the pre-departure plan of a future assignee. Transmission of the personal experience is priceless. The intercultural preparation would be recommended to start as soon as possible and include the accompanying family as well. Moreover, some general intercultural courses should be offered to every employee, regardless the possibility of international assignment.

Intercultural trainings could be improved by the concentration on the whole assignment and do not only rely on pre-departure preparation. The development of intercultural competences is a process and should not leave the focus of the human resource management department when the expatriate manager leaves the home country. Another possibility how to improve the preparation of future expatriate is to use the employees that have already experienced an assignment of similar kind. The human resource managers should ask about their experience, process the feedbacks and information and provide the opportunity to share it.

Particularly, language barriers are considered one of the major problems when employees are assigned to Asian countries. Although many companies offer language courses for their employees, they often underestimate the language factor when selecting the right people for foreign assignments (Puck et al. 2008). Therefore, the importance should be given to the language courses and to assess the language level of an expatriate candidate as a part of selection process. That should be a prerequisite to actually consider the person for the foreign assignment. Moreover, language barrier might also be a potential threat for the adjustment of the expatriate's family.

In our point of view, training institutes and multinational corporations themselves need to collaborate with researchers to evaluate their training programs in order to maximize their potential. Moreover, these trainers often do not get the feedback on the expatriates' adjustment abroad as the expatriates' performance is a matter of the company's management.

This paper contributes to the existing knowledge by the primary data obtained from the Czech expatriates. As Puck et al (2008) confirm, there is a lack of research on this topic in terms of non-US expatriates. Although the data comes from one organizational environment, this company was chosen on the basis of its long-term and extensive experience with the process of expatriation together with the services provided by its human resource department, which is hardly comparable with another company in the Czech Republic.

\section{Acknowledgement}

This paper was prepared with institutional support of the long-term conceptual development of the Faculty of Economics, Technical University of Liberec, in the framework of the project Excellent Research Teams - Business in International Trade. 


\section{References}

[1] BENNETT, R., A. ASTON and T. COLQUHOUN, 2000. Cross-cultural Training: A Critical Step in Ensuring the Success of International Assignments. Human Resource Management, 39, 239-250.

[2] BHASKAR-SHRINIVAS, P., D. A. HARRISON, M. A. SHAFFER and D. A. LUK, 2005. Input-based and time-based models of international adjustment: Meta-analytic evidence and theoretical extensions. Academy of Management Journal, 48(2), 257-281. ISSN 00014273 .

[3] BLACK, S., H. B. GREGERSEN and M. E. MENDENHALL, 1992. Global assignments: Successfully expatriating and repatriating international managers. Jossey-Bass. ISBN 9781555424732.

[4] BRIGHT, C. C., 2008. Investigating the relationship between expatriate adjustment, marital status, and related attributes. University of Phoenix, ProQuest Dissertations Publishing, ISBN 3364166.

[5] BREWSTER, CH., 1995. Towards a 'European' model of human resource management. Journal of International Business Studies, 26(1), 1-21. ISSN 0047-2506.

[6] BROOKFIELD, 2015. 2015 Global Mobility Trends Survey Report: Mindful Mobility [online]. Brookfield Global Relocation Services. [cit. 2018-02-23]. Dostupné z: http://globalmobilitytrends.brookfieldgrs.com/\#?q=5

[7] DORFMAN, P. et al., 2012. GLOBE: A twenty year journey into the intriguing world of culture and leadership. Journal of World Business, 47(4). 504-518. ISSN 1090-9516.

[8] DOWLING, P., M. FESTING and A. ENGLE, 2008. International Human Resource Management: Managing People in a Multinational Context. Hampshire: Cengage Learning.

[9] ECA INTERNATIONAL, 2016. Cost of total expatriate pay package in Taiwan falls by 6\% in past year [online]. UK: ECA International. [cit. 2018-04-29]. Dostupné z: https://www.eca-international.com/news/july-2016/cost-of-total-expatriate-pay-packagein-taiwan-fal

[10] HARRIS, H., 2004. Global careers: Work-life issues and the adjustment of women international managers. Journal of Management Development, 23(9), 818-832. ISSN 0262-1711.

[11] HARRISON, J. K., 1994 Developing successful expatriate managers: A framework for t. People and Strategy, 17(3), 17. ISSN 1946-4606.

[12] HECHANOVA, R., T. A. BEEHR and N. D. CHRISTIANSEN, 2003. Antecedents and consequences of employees adjustment to overseas assignment: A meta-analytic review. Applied Psychology: An International Review, 52(2), 213-236. ISSN 1464-0597.

[13] HILL, C. W., 2010. International Business: Competing in the Global Marketplace. (8th ed.), Englewood Cliffs: Irwin McGraw-Hill.

[14] KOGUT, B., 2000. The Network as Knowledge: Generative Rules and the Emergence of Structure. Strategic Management Journal, 21, 405-425.

[15] LENARTOWICZ, T., J. P. JOHNSON and R. KONOPASKE, 2014. The application of learning theories to improve cross-cultural training programs in MNCs. The International Journal of Human Resource Management, 25(12), 1697-1719. 
[16] MENDENHALL, M. E. and G. ODDOU, 1988. The overseas assignment: A practical look. Business Horizons, 31(5), 78-84. ISSN 0007-6813

[17] MENDENHALL, M. E., B. J. PUNNETT and D. RICKS, 1995. Global management. Cambridge, Mass: Blackwell Publishers. ISBN 978-1557866356.

[18] MORRIS, M. A. and CH. ROBIE, 2001. A meta-analysis of the effects of cross-cultural training on expatriate performance and adjustment. International Journal of Training and Development, 5(2), 12-125. ISSN 1468-2419.

[19] NOVÝ, I. et al., 1996. Interkulturální management: Lidé, kultura a management. Praha: Grada. ISBN 80-7169-260-3.

[20] PUCK, J. F., M. G. KITTLER and CH. WRIGHT, 2008. Does it really work? Re-assessing the impact of pre-departure cross-cultural training on expatriate adjustment. The International Journal of Human Resource Management, 19(12), 2182-2197.

[21] REY, J., CARO, F. J. and S. BALHADJ, 2017. The challenges of intercultural communication if the age of globalization: The case of Spanish companies based in Morocco. Prisma Social, 17, 415-437.

[22] SHMUELI, R., S. L. DOLAN and J. L. CERDIN, 2005. Emotional intelligence as predictor of cultural adjustment for success in global assignments. Career Development International, 10(5), 375-395. ISSN 1362-0436

[23] THOMAS, D. C. and M. B. LAZAROVA, 2006. Expatriate adjustment and performance: a critical review. In G. STAHL and I. BJORKMAN, ed. Handbook of Research In International Human Resource Management. Edward Elgar Publishing, Cheltenham, 2006, 247-264. ISBN 1845421280.

[24] TUNG, R. L., 1981. Selection and training of personnel for overseas assignments. Columbia Journal of World Business, 16, 68-78. ISSN 0022-5428.

[25] TUNG, R. L., 1998. American expatriates abroad: from neophytes to cosmopolitans. Journal of World Business, 33(2), 125-44. ISSN 1090-9516.

[26] TUNG, R. L. and A. ANDERSEN, 1997. Exploring international assignees' viewpoints: A study of the expatriation/repatriation process. Chicago IL: Arthur Anderson, International Executive Services. 